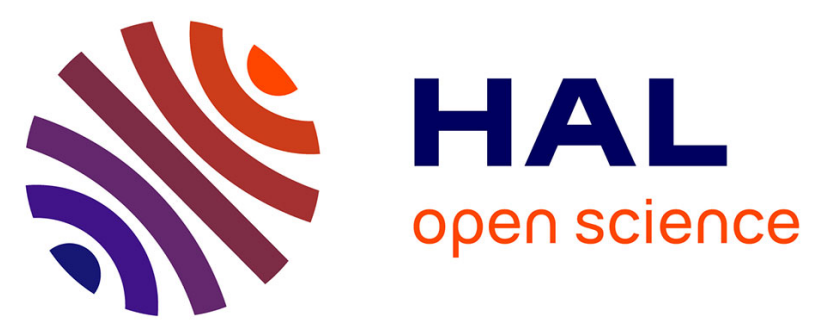

\title{
The National Pediatric Surgery Simulation Program in France: A tool to develop resident training in pediatric surgery
}

\author{
Jean Breaud, Isabelle Talon, Laurent Fourcade, Guillaume Podevin, Julien \\ Rod, Georges Audry, Bruno Dohin, Jean-Francois Lecompte, Ronny Bensaid, \\ Virginie Rampal, et al.
}

\section{To cite this version:}

Jean Breaud, Isabelle Talon, Laurent Fourcade, Guillaume Podevin, Julien Rod, et al.. The National Pediatric Surgery Simulation Program in France: A tool to develop resident training in pediatric surgery. Journal of Pediatric Surgery, 2019, 54, pp.582 - 586. 10.1016/j.jpedsurg.2018.09.003 . hal03486022

\section{HAL Id: hal-03486022 \\ https://hal.science/hal-03486022}

Submitted on 20 Dec 2021

HAL is a multi-disciplinary open access archive for the deposit and dissemination of scientific research documents, whether they are published or not. The documents may come from teaching and research institutions in France or abroad, or from public or private research centers.
L'archive ouverte pluridisciplinaire HAL, est destinée au dépôt et à la diffusion de documents scientifiques de niveau recherche, publiés ou non, émanant des établissements d'enseignement et de recherche français ou étrangers, des laboratoires publics ou privés.

\section{(ㄷ)(1) $\$$}

Distributed under a Creative Commons Attribution - NonCommerciall 4.0 International 
Title: The National Pediatric Surgery Simulation Program in France : a tool to develop resident training in pediatric surgery.

Authors:

Jean Breaud

Medical Simulation Center - Cote d'Azur University - Faculté de Médecine de Nice . 28 avenue de Valombrose. 06000 Nice (France).

Pediatric Surgery Department. Hôpitaux Pédiatriques de Nice CHU-Lenval. 57 avenue de la californie. 06200 Nice (France).

Email : breaud.j@pediatrie-chulenval-nice.fr

Isabelle Talon

Pediatric Surgery Department CHU de Strasbourg . Hopital de Hautepierre. 1 avenue Moliere. 67200 Strasbourg (France).

\section{Laurent Fourcade}

Pediatric Surgery Department. CHU de Limoges. Hopital de la Mère et de l'Enfant. 8 avenue Dominique Larrey. 87000 Limoges (France).

Guillaume Podevin

Pediatric Surgery Department. CHU d'Angers. 4 rue Larrey. 49933 Angers cedex 9 (France).

\section{Julien Rod}

Pediatric Surgery Department. CHU de Caen. Avenue de la Côte de Nacre. CS 30001. 14033 Caen Cedex 9 (France).

Georges Audry

Pediatric Surgery Department. Hopital Armand Trousseau. APHP. 26 avenue du Dr Arnold Netter.75012 Paris (France).

\section{Bruno Dohin}


Pediatric Surgery Department. CHU de Saint Etienne. Avenue Albert Raimond. 42270 SaintPriest-en-Jarez

\section{Jean-Francois Lecompte}

Pediatric Surgery Department. Hopitaux Pédiatriques de Nice CHU-Lenval. 57 avenue de la californie. 06200 Nice (France).

\section{Ronny Bensaid}

Pediatric Surgery Department. Hopitaux Pédiatriques de Nice CHU-Lenval. 57 avenue de la californie. 06200 Nice (France).

\section{Virginie Rampal}

Pediatric Surgery Department. Hopitaux Pédiatriques de Nice CHU-Lenval. 57 avenue de la californie. 06200 Nice (France).

\section{Georges Azzie}

Pediatric Surgery Department. Sick Children Hospital. 555 University Avenue, Toronto, ON M5G 1X8, Canada.

\section{Corresponding author :}

Jean Breaud. Pediatric Surgery Department. Hopitaux Pédiatriques de Nice CHU-Lenval. 57 avenue de la californie 06200 Nice (France).

Email : breaud.j@pediatrie-chulenval-nice.fr 


\section{Introduction:}

The training of Pediatric Surgeons in France, as elsewhere, relies on the acquisition of the requisite knowledge and skill. These cognitive abilities and technical skills are taught through a combination of didactic sessions, patient related activities (in and out of the operating room), and most recently, simulation based modalities. This paper will focus on the formalized national simulation curriculum in France.

The "raison d'être" for developing and formalizing a nationwide simulation program in Pediatric Surgery has to do with the very nature of the specialty. As few others, Pediatric Surgery is set apart from most other surgical specialties in several ways: the complex tripartite relationship between patient, parents and surgeon, the great variability and complexity of cases, and the rarity of the many conditions [1] By virtue of theses, it is a challenge for trainees to develop the skill sets required. The specialty demands expertise in many domains, which range from the traditional technical [2] and cognitive realms to the equally important realms of communication, collaboration, and patient advocacy.

As in many other countries, trainees in France had little or no formal teaching and assessment of skills revolving around communication, collaboration, patient advocacy and applied clinical judgment. [3] Having recognized these shortcomings, a task force was created to develop strategies that would help address these realms, as well as optimize the teaching of traditional cognitive and technical competencies. Established teaching modalities were optimized, and a newer modality, simulation, became an integral part of training. Of particular interest, it was decided that the course would be adopted by all training programs, at a national level.

The interest in simulation stemmed from evidence that such programs targeting either technical skills ("how to do") or communication and collaboration skills ("how to behave"), have proven their suitability in medical and surgical training, and are a valuable adjuncts to traditional training methods. [4]

The next challenge to implementation of a national simulation program in France was that access to simulation for pediatric surgical trainees was heterogeneous. There was significant variability based on local aspects (physical availability of a surgical simulation center in the medical school, and whether there was even a local interest to develop an educational program in simulation). This variability meant that to develop a nationwide program, training centers would have to be willing to collaborate in the development of a national simulation course.

With these challenges in mind, and with an ultimate goal to provide the highest quality training possible, the national council, known as the "Collège Hospitalier et Universitaire de Chirurgie Pédiatrique", examined the relevance and feasibility of systematically introducing simulation training as part of a nationwide pediatric surgery resident training program in France. This would not only supplement the traditional schemes, but eliminate much of the heterogeneity in training, and afford uniform access across the country. 
Thus, a national simulation training program (NSTP) for pediatric surgery was created. This study reviews the program's development, describes its implementation, examines the initial results, and discusses its future prospects.

\section{$\underline{\text { Materials and Methods }}$}

Program design:

The NSTP was developed by the authors. Each is involved (board chair/trainer) in their respective simulation centers, and each is experienced in medical simulation training.

This program was created over a 3-year period. The initial concept was the brainchild of one of the authors (JB). The program was subsequently designed by national and international stakeholders who collaborated through working groups. This was all done with the supervision and guidance of the Collège Hospitalier et Universitaire de Chirurgie Pédiatrique.

An initial feasibility analysis was conducted, taking into account the number of residents in training, the number of potential trainers, and the available infrastructure (medical simulation centers) in the country.

Practical organization:

The nationwide program would take place annually, over a two day training course. To decrease the expenses related to travel for both residents and trainers, and in order to maintain a satisfactory teacher/student ratio, a cross-regional organization was implemented in 7 simulation centers throughout France. The program was identical in all centers. Each regional simulation center had appropriate equipment (dry lab with simulators and laparoscopic instruments, dedicated room for communication training, access to OR and/or virtual OR). A regional coordinator and appropriate faculty members from each regional School of Medicine were identified. The regional coordinator had to be a senior pediatric surgeon, a member of faculty in the local medical school, and a member of faculty or board chair in the local simulation center. Teaching faculty had to be senior Pediatric Surgeons with a faculty appointment at their respective school of medicine, and have training in simulation. Volunteers served as actors in scenario based simulation.

The outline of the NSTP was sent to each regional coordinator three months before the course. Prior to the course, a face to face meeting was held with all faculty members in order to present the entire NSTP curriculum.

\section{$\underline{\text { Training Content }}$}

The program dealt with technical ("how to do") and non technical ("how to behave") skills.

Residents would take part in each of three workshops:

The "communication" workshop was based on standardized consultations (20 min), with 2 actors (medical/paramedical students/trainers) as parents, followed by a debriefing period (20 min) with the faculty member and, if available, a psychologist. Each scenario had specific goals regarding information to be delivered (or not be delivered) to parents, based on an established check list. The global verbal and non verbal communication was assessed and discussed during the debriefing with the faculty member and the psychologist. 
Among the six increasingly complex scenarios (Table 1) that were proposed, each resident had to complete at least four scenarios. These scenarios enabled the surgeon-in-training to confront common clinical situations, rare situations, potentially stressful situations, and situations with complex personalities. Scenarios were selected by the faculty member on the basis of the level of the resident ( $1^{\text {st }}$ to $5^{\text {th }}$ year resident).

The "teamwork" workshop was based on an operating room role-play with a mannequin (or virtual operating room), equipment and staff as in a normal procedure. The scenario was developed to target "error prevention training":

It involved a 9-month-old infant (mannequin) undergoing exploratory laparoscopy for a nonpalpable testis. The surgeon-in-training was expected to demonstrate the ability to avoid a pre-determined number of errors (Table 2) made by the care team, prior to actually beginning the case.

The scenario lasted 20 minutes, beginning when the trainee enters the OR, and extending to the "time out" before the actual incision. During this period, team members in the OR take care of the patient (installation, dressing, local anesthesia...) and the resident was expected to prepare and check all the key points prior to incision. The scenario is supervised by a faculty member, and debriefing is done during a 20 minute session with all the staff.

The "technical" workshop included

- laparoscopic training on adult (FLS [1]* or equivalent) and pediatric (PLS[2]*) simulators focusing on basic techniques, suturing, and more advanced techniques. Low-fidelity surgical models (pyeloplasty, esophageal atresia) have been developed and are being used.

- Open surgical skills involving delicate suturing under magnification.

\section{NSTP Assessment}

For the trainees, each workshop was assessed with a scenario-specific or exercise-specific assessment grid:

- for the communication scenarios, each contained its own training objectives, and the communication was assessed according to the National Health Authority (HAS) methodology grid [7].

- For the teamwork workshop, each training objective (Table 2) was expected to be met, and the communication was assessed separately.

- For the techniques, the exercises were assessed using OSATS* scores [8].

- The NSTP was assessed by each resident (participant), and each faculty member, using a composite assessment (including a score out of 20, free comments, closeended questions, and a Likert scale) (Table 3):

The overall assessment of the NSTP included an assessment of the seminar (duration: from too short, to adequate, or too long, schedule intensity, location, training objectives, number of scenarios, seminar frequency). In order to assess the level of satisfaction across regions, participants were asked: "are you satisfied by the cross regional organization (Yes/No)". The communication scenarios were assessed on a Likert scale. The levels of satisfaction with the technical training components were also assessed. 
The educational value of the seminar was assessed via a Lickert scale on 5 points, from 1 (very low educational value) to 5 (very high educational value). An overall score for the NSTP, as well as for the quality of the teaching were required.

The assessment by faculty members focused on the difficulties encountered, and on the points to be improved.

Results:

Attendance: 40 residents in pediatric surgery (or $95 \%$ of the residents enrolled in the national training scheme) participated in the first annual NSTP session, including $62 \%$ in their $4^{\text {th }}$ or $5^{\text {th }}$ year of residency (Figure 1 ).

Number of members of faculty: 20 faculty members (senior surgeons/simulation trainers) were present.

The courses were took place in 7 simulation centers across the country, based in the major metropolitan areas (Amiens, Strasbourg, Limoges, Nice, Paris, Angers, Grenoble).

General organization:

Duration of training ( 2 day session) was deemed appropriate for $92.5 \%$ of respondents, while too short for $7.5 \%$ of respondents, and a comparable level of satisfaction was found regarding the intensity of the schedule (appropriate for $92.5 \%$ of respondents, while too light for $7.5 \%$ of respondents).

There was $97.5 \%$ satisfaction with the cross-regional organization.

The number of faculty per resident was satisfactory for $82 \%$ of respondents, too low for $16 \%$ of respondents, and too high for $2 \%$ of respondents.

The frequency (annual) was too low (more than one session per year requested) for $79 \%$ of respondent trainees, satisfactory for $18 \%$ of respondent trainees, and too high for $3 \%$ of respondent trainees.

Training program:

The training objectives earned a score of $4.46 / 5$ on the identified Likert scales.

In more detail, the number of scenarios proposed was deemed satisfactory for $92 \%$ of respondents, too many for $5 \%$ of respondents, and insufficient for $2 \%$ of respondents.

The six proposed standardized consultation scenarios scored between 4.3 and 4.7/5.

The teamwork workshop scenario ("error prevention training") scored 4.4/5.

The time allotted for surgical technique/technical skills was deemed appropriate for $71 \%$ of respondents, too short for $37 \%$ of respondents and too long for $2 \%$ of respondents.

The equipment used for surgical technique/technical skills was deemed satisfactory for $87 \%$ of respondents and extremely satisfactory for $13 \%$ of respondents. 
The interventional models used for laparoscopy were deemed appropriate for $73 \%$ of respondents and highly relevant for $27 \%$ of respondents.

Overall assessment for the inaugural NSTP:

The educational value of the seminar scored $4.7 / 5$, the quality of the teaching was felt to be $17.95 / 20$ and the overall score for the seminars was 17.35/20.

\section{$\underline{\text { Discussion }}$}

A pediatric surgeon's daily activity requires two major skill sets:

1) "Non technical skills" are necessary for patient consultation and follow-up in hospital. They involve not only appropriate knowledge of the conditions, but a set of communication skills tailored to the child, regardless of his/her age, which also meet the expectations of parents, regardless of how stressful the situation.

These "non technical skills" are also essential for directing the surgery, and leading a team by using clear, effective, and reassuring collaborative skills.

2) "Technical skills" which are essential for surgical activity requiring technical ability.

At present, training for young surgeons in France is organized under the auspices of University Boards specific to each surgical specialty. These boards set the training model throughout the residency.

In pediatric surgery, this training takes place in formal residency training programs (throughout 32 University Medical Centers in France). This involves theoretical teaching (50 hours/year) over 3 years, a national and annual monothematic training conference and a "logbook" listing the training objectives.

Of particular relevance for the current surgical training in France, recent legislation (legislation regarding work time in hospital, on-call rest, administrative constraints) has led to a reduction in residents' hospital time, in parallel with an decrease of number of new resident due to in the numerus clausus. Moreover, the new residency reform releases residents from their hospital activities for 2 half-days per week [9]. All these factors contribute to an undermining of the traditional mentorship and training, with decreased in-person operating room time, and an estimated shortening of overall training equal to one year! Trainees themselves have recognized the problem, and the vast majority have compensated for this perceived deficit by enrolling for supplementary university diplomas at their own expense. As a result, training has become heterogenous by virtue of the supplementary training available to some but not to others (based on availability and the student's financial resources).

All these constraints have heightened the trainee's focus on the technical side of the specialty. Resident training focuses on technical ability and experience in the operating room. As a result of this, skill sets addressing communication and collaboration take a back seat to the traditional cognitive and technical skills. Residents have become obsessed with the need to "learn to operate". 
A national survey conducted in 2016 identified that pediatric surgery residents performed on average four specialist consultations per semester. The survey highlighted that they did not feel confident in complex situations, and strongly wanted to have supplementary training [10]. Of interest, a lack of training in the area of prenatal consultations has also been identified in other countries, such as the USA [11].

In a similar vein, there is currently no "teamwork" training, even though it is widely recognized that in settings such as the operating room and other hospital departments, communication skills are essential. This has been proven by an analysis of adverse events in hospital departments which reported that, in 1/4 of cases, medical errors are linked to communication failures between professionals, mostly under stressful conditions such as in an operating room setting [12-13].

Given the current evolution in surgical practice, and the changes in the training programs, we recognized that the current training system was sub-optimal. We looked for an alternative methodology to ensure the highest quality training in light of all the constraints outlined above. Simulation training techniques have been proven in all areas of learning [7]. The positive impact of simulation training was identified a dozen years ago, both for acquiring technical skill and for shortening the learning curve [14-15]. As important, this is also true in the areas of communication and teamwork [16-17], although this evidence has only come to light much more recently. More specifically, the impact of simulation has been highlighted when training for "difficult" or stressful situations, such as reporting bad news [18], or pediatric resuscitation [19], following the crisis resource management (CRM) model.

Pediatric surgery seems particularly likely to benefit from simulation training, due to the characteristics of this specialty: wide variability in techniques [2], small work spaces, rare indications, and thus a potentially long "learning curve". Equally important are the increased importance of communication and collaboration skills for teamwork, and especially for the particular relationship that exists in the child-parent-physician triad. The advantage of integrating a non technical skills training section by using pediatric surgery consultation scenarios is that the surgeon-in-training will be sensitized its importance, and have some experience to help deal with such situations. This is true of situations ranging from common scenarios during which all the information must be clearly and appropriately communicated, to stressful situations in which the surgeon must be prepared to better deal with his/her own emotions, to situations where the personality of those with whom the surgeon is dealing weakens the physician-patient relationship and the required confidence to deliver appropriate patient care. Being able to encounter each of these situations during simulated exercises fosters a better understanding of the difficulties inherent in each. Prior exposure enables the development of soft skills, and allows the surgeon to know himself/herself better, becoming more sensitized to elements that strengthen or, conversely, weaken, communication, and thus patient care (vocabulary, positions, gestures, etc.).

In pediatric surgery, simulation traditionally targets mainly technical training, using multiple models and validated interventional support [20-21]. These allow acquisition of the technical skill, but rarely address "non technical skills". The objective of our national program is the acquisition of both "technical" and "non technical" skills for all trainees. The development of the program required two major elements. The first involved the creation of a "task force" 
made of French pediatric surgeons involved in simulation training. They thoughtfully outlined a program that would satisfy our educational goals. The second involved convincing the National Board (Collège Hospitalier et Universitaire de Chirurgie Pédiatrique) to formalize and make mandatory a national program. The implementation then became a question of logistics: establishing a framework of nationwide access to educators and infrastructures of sufficient quality.

The national program has proven to be effective, and has been very favorably accepted, allowing small-group training, with a high teacher/student ratio (1 trainer for 2 residents), in dedicated, recognized medical simulation centers (universities) at low cost (limited travel for residents and trainers).The training program has been assessed favorably by participants, whether on the basis of distribution among the three activities (consultation, error training, technical skills) or relevance of the scenarios and exercises, and it has received excellent assessment in terms of quality of training. The variability and versatility of scenarios used for consultations (from simple to more complex situations) seems to be well adapted to participants at all levels of training. For example, the error training scenario was rated as very interesting for all participants (junior and senior).

Some results of the participant and faculty assessments indicate ways in which to improve the NSTP. For the residents, the frequency seems insufficient and they would like (in $82 \%$ of cases) to have two training sessions per year. Results also reveal that, to a lesser extent, they would appreciate more time given to technical training (71\% satisfaction).

On the whole, the program was liked by faculty members. They did however highlight that the program is time-consuming and labor-intensive. Using medical students as actors, trained by the trainers as proposed by Emerson [22], has been shown to be effective and seems to be a way to control the required human resources, as well as to address the financial constraints of running such a program (no need for formal actors).

Moving forward, the NSTP will target: 1) a growing number of standardized consultation and multidisciplinary role play scenarios, and 2) implementation of a second annual training session. A specific goal regarding program content for senior trainees will be the development and integration of multidisciplinary scenarios regarding stressful situations. There is good evidence that these could improve and consolidate knowledge. This fact, in conjunction with our recognition of the importance for our trainees, justify the development of this scenariobased training [23-24]. Another potential target is to explore and implement more of the growing number of simulators for technical training.

Ultimately, we would like to disseminate our experience outside of France, and help contextually develop and apply similar programs in other countries, sharing the lessons we have learned.

\section{Conclusion}

Based on an initiative by the National Board of Pediatric Surgery, a mandatory national simulation training program was designed and implemented in France. This program addresses both "technical" and "non technical" skills for trainees in Pediatric Surgery. This unique program has been very favorably assessed by the participating residents and by the 
involved faculty. To our knowledge, it represents the first mandatory national surgical simulation training program addressing both "technical" and "non-technical" skills.. This program will now be an integral part of pediatric surgical training in France, and may serve as a model to the development and implementation of pediatric surgical training in other countries. 
Figure 1: repartition of resident's years of study.




Table 1: Standardized Communication Scenarios

\begin{tabular}{|l|l|}
\hline Scenario 1 & $\begin{array}{l}\text { Unilateral non-palpable testis in a 9-month- } \\
\text { old child. Report the indication for surgery } \\
\text { and the different possible situations. }\end{array}$ \\
\hline Scenario 2 & $\begin{array}{l}\text { Report a perioperative complication: } \\
\text { conversion from partial laparoscopic } \\
\text { splenectomy o open total splenectomy due } \\
\text { to vascular injury }\end{array}$ \\
\hline Scenario 3 & $\begin{array}{l}\text { Report a postoperative complication: } \\
\text { urinoma secondary to uretero-pelvic } \\
\text { junction surgery on post-operative day 3 }\end{array}$ \\
\hline Scenario 4 & Report discovery of an abdominal tumor \\
\hline Scenario 5 & $\begin{array}{l}\text { Prenatal consultation: } \\
\text { Discovery on the ultrasound of a suspected } \\
\text { congenital uropathy (unilateral uretero- } \\
\text { pelvic dilation) }\end{array}$ \\
\hline Scenario 6 & $\begin{array}{l}\text { Prenatal consultation: } \\
\text { Discovery of gastroschisis (consultation at } \\
\text { 22 weeks of gestation) }\end{array}$ \\
\hline
\end{tabular}


Table 2: Multidisciplinary Scenario: "Error Prevention Training" - Training Objectives

\begin{tabular}{|l|l|}
\hline Objective 1 & Verify patient identify \\
\hline Objective 2 & Verify record is present \\
\hline Objective 3 & Read the medical record \\
\hline Objective 4 & Verify electro-cautery settings \\
\hline Objective 5 & Verify insufflator settings \\
\hline Objective 6 & $\begin{array}{l}\text { Monitor incision site/loco-regional anesthesia } \\
\text { dressing location }\end{array}$ \\
\hline Objective 7 & $\begin{array}{l}\text { Verify patient positioning before pre-defining } \\
\text { fields }\end{array}$ \\
\hline Objective 8 & Verify electro-cautery device and position \\
\hline Objective 9 & Verify lighting (operative light position) \\
\hline Objective 10 & Position laparoscopic tower \\
\hline Objective 11 & Perform Check-list (time out) \\
\hline Objective 12 & fix cables/tubes after defining fields \\
\hline
\end{tabular}


Table 3: Evaluation Grid for Trainees

1. Year of residency : $1^{\text {st }} \quad 2^{\text {nd }} \quad 3^{\text {rd }} \quad 4^{\text {th }} \quad 5^{\text {th }}$

2. Global evaluation of the program :

a. Duration : too short adequate too long

b. Location : are you satisfied with the cross-regional organization : yes/no

c. Pedagogic goals : Lickert scale from 1 (not adapted at all ) to 5 (high adaptation to resident training) : $1 \quad 2 \quad 3 \quad 4 \quad 4 \quad 5$

d. Number of scenario : not enough enough too numerous

e. Number of trainers : insufficient adequate too numerous

f. Annual frequency : insufficient adequate too high

3. Evaluation of scenario : utilization of a Lickert scale from 1 to 5 . ( $1:$ bad quality or not adapted to the situation $-3:$ correct $-5:$ high adaptation and/or relevant)
a. Scenario 1 :
b. Scenario 2 :
c. Scenario 3 :
d. Scenario 4 :
e. Scenario 5 :
f. Scenario 6 :
g. "teamwork workshop":

4. Laparoscopic and suturing workshop:
a. Duration : too short
adapted too long
b. Material : not enough adapted
very efficient
c. Models used : not adapted adapted
very relevant

5. Overall evaluation of the program : / $20 \mathrm{pts}$

6. Teaching quality of the program : /20 pts

7. Pedagogic value of the program : Lickert scale on 5 points $(1:$ very low -5 very high): $1 \quad 2 \quad 3 \quad 4 \quad 5$

8. Free comments about the program : 